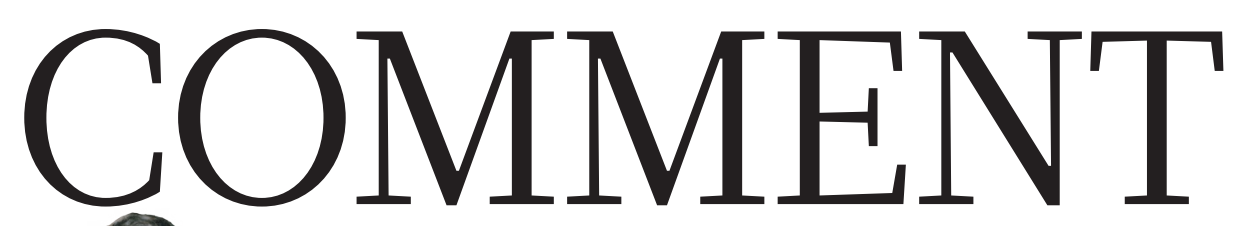

BIOETHICS Flowers for Her HISTORY The Victorian female Algernon is still powerful surgeon who had to pose 50 years on $\mathbf{p . 3 9 4}$ as a man $\mathbf{p} .395$

BRAIN DRAIN Venezuela is haemorrhaging its leading researchers $\mathbf{p . 3 9 6}$
OBITUARY Alfred G. Knudson, cancer-genetics pioneer, remembered $\mathbf{p . 3 9 7}$

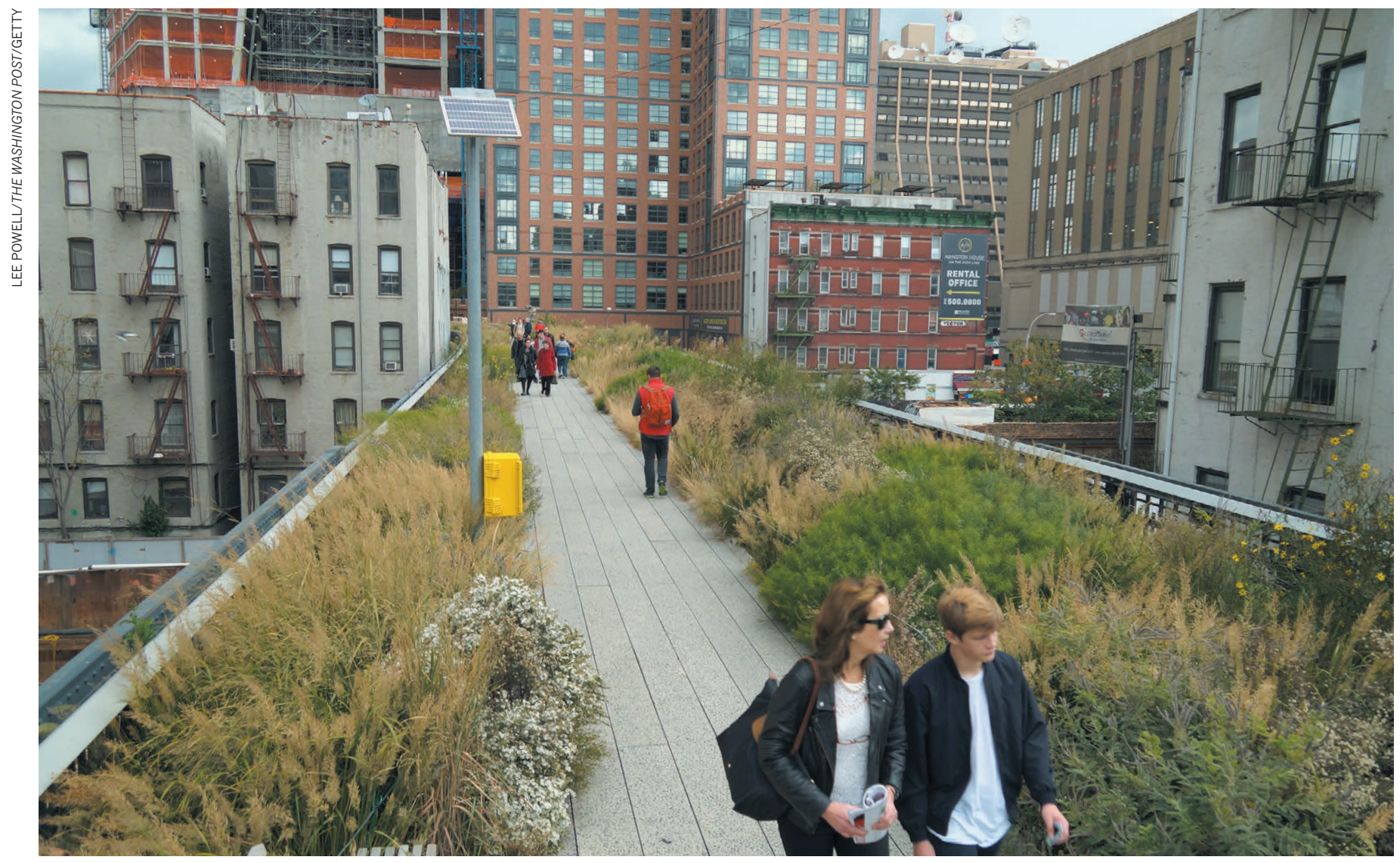

New York City's High Line park, a transformed former rail line.

\title{
Expand the frontiers of urban sustainability
}

Social equity and global impacts are missing from measures of cities' environmental friendliness, write David Wachsmuth, Daniel Aldana Cohen and Hillary Angelo.

$\mathrm{M}$ anhattan skyscrapers, rather than rustic rural towns, are quickly becoming the picture of sustainable living in the twenty-first century. San Francisco, Copenhagen and Singapore each top their regions in the Green City Index (see go.nature.com/2bxjac9). As sites of innovation and economic dynamism, these places exemplify a blend of density and livability that large, prosperous cities in the 'global south', such as Mumbai in India and São Paulo in Brazil, increasingly emulate.

A few decades ago, cities were seen as sustainability problems rather than solutions. Then, as concerns about suburban sprawl, shanty towns and climate change grew, so too did awareness that clustering people in energy-efficient buildings and walkable, shady neighbourhoods makes cities more pleasant to live in and better for the global environment.

But the prevailing model of urban sustainability is too narrow. Although the social, economic and ecological issues behind sustainability problems are regional or global in scale, urban policy usually addresses single ecological 
> issues in individual neighbourhoods. Focusing on dense cities and their affluent areas ignores social movements and their advocacy for quality-of-life issues such as housing and commuting, which have direct ecological consequences. Targeting specific districts ignores the often negative regional and global impacts of local environmental, or 'greening', improvements.

Spatially, sustainability research and policymaking should shift focus from

\section{"Even information in 'the cloud'} has an environmental impact."

city centres to urban regions and global networks of production, consumption and distribution. Socially, policymakers should incorporate equity into every stage of the urban-policy process, from research to formulation to implementation.

\section{NEIGHBOURHOOD WATCH}

From the revitalization of city parks to urban bicycle-sharing programmes, urban sustainability interventions tend to be conceived, implemented and evaluated one municipality or neighbourhood at a time. Yet urban environmental processes occur on much larger scales. Projects that benefit one district may have negative impacts next door.

One example is environmental gentrification. As districts become greener, they become more desirable and expensive. The premiums placed on neighbourhood amenities - such as walkability, public transport and the proximity of parks, farmers' markets and 'greenways' such as hiking trails and bike paths - by residents who can afford to pursue them raise the cost of living.

Social displacement can result. Policies that encourage these improvements tend not to be linked to a broader social-equity agenda, so low- and middle-income residents are forced into peripheral neighbourhoods where population densities are lower, commutes are longer and environmental problems are more common. Many sustainability gains are simply a regressive redistribution of amenities across places.

For example, in North American cities such as New York and San Francisco, poor districts have long suffered from the dumping of industrial-waste, low air quality and a lack of green spaces. In recent years, often in response to community activism, policymakers have tried to create shadier streets and more recreational space, to improve public transport and greenway access, and to build mixed-use eco-friendly housing in such neighbourhoods. New York City has made efforts to green East Harlem, western Queens and Red Hook in Brooklyn. Yet poor people are frequently priced out and must move ${ }^{1}$.
In Europe, the German city of Freiburg has been internationally recognized for its achievements in renewable energy, public transport, participatory planning and pedestrianized, energy-efficient districts. As the metropolitan region has become more desirable and expensive, more of its workforce has turned to the cheaper suburbs for housing. The city has grown more socially homogenous, while beyond its boundaries commuting has skyrocketed, as have the associated carbon emissions ${ }^{2}$. Greening has come at the expense of community stability and racial and economic diversity, and has undermined regional environmental goals.

These patterns hold around the world. Studies have shown that in several cities, the social costs of climate adaptation fall mainly on disadvantaged groups. Examples include Medellín, Colombia; Jakarta, Indonesia; Dhaka, Bangladesh; and Boston, Massachusetts. Climate-adaptation plans fail to engage poor communities and often recommend relocating them to unsafe areas where they would be more vulnerable to droughts, heat, flooding and disease. Meanwhile, wealthy residents who set the planning agenda benefit from new land-use regulations and protective infrastructure. From Boston to Dhaka, resources earmarked for climate-adaptation are concentrated in wealthy districts and the risks are exacerbated elsewhere ${ }^{3}$.

\section{FARTHER AFIELD}

Post-industrial cities highlight their sustainability triumphs in terms of building density, extensive public-transport networks and the presence of knowledge-intensive, hightech firms, all of which drive down locally

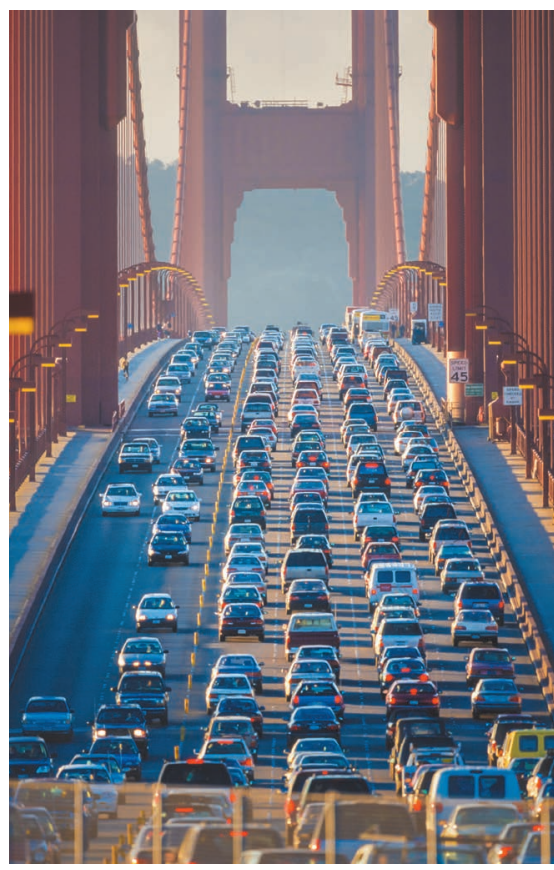

The Golden Gate Bridge in San Francisco. produced pollution and carbon emissions. But even high-tech workplaces depend on polluting activities elsewhere. Computers and smartphones produce growing global flows of electronic waste that concentrate their toxic by-products - such as the trace amounts of beryllium and mercury in mobile phones - in poor communities in the developing world. Guiyu in China used to be a small rice-growing village, but was transformed in the 1990s into the world's largest processing zone for electronic waste. Local water rapidly became undrinkable ${ }^{4}$.

Even information in 'the cloud' has an environmental impact. Data centres account for $2 \%$ of global greenhouse-gas emissions; their power usage is expected to triple in the next decade ${ }^{5}$. And much financial and high-tech activity consists of coordinating resource extraction and manufacturing activities that have moved to other parts of the globe. Apple designs its iPhones in California, but $84 \%$ of the embodied carbon emissions of the phones come from their production in China, South Korea and other countries, mostly in Asia.

The low-carbon footprints prized by cities such as San Francisco and Seattle are little more than accounting tricks. The main method of carbon counting attributes to urban areas only the emissions resulting from in-city activities and regional power plants. Few studies count the full life cycle of emissions for all goods and services consumed by individuals and groups in cities, or emissions resulting from air travel. Those that do are telling. Consumptionbased carbon counts for Shanghai, Seattle, San Francisco and London find more than double the per capita emissions of standard calculations. Almost $80 \%$ of San Franciscans' greenhouse-gas emissions, for example, are produced outside the city ${ }^{6}$ (see 'Remote impacts').

The apparent low-carbon benefits of density fall dramatically when income and lifestyle are controlled for. Upper-income urban residents in the United States and Europe tend to consume more imported goods and services, fly more often, and drive out of the city more often than people living on lower incomes ${ }^{7}$. In the United Kingdom, during the explosion of lowcost air travel from the late 1980s to the early 2000s, the number of working-class passengers flying out of London increased by around $60 \%$; wealthy passengers' trips increased by nearly $150 \%$.

Although prosperous urban residents may commute by bicycle or public transport - the forms of low-carbon living most commonly cultivated by sustainability projects such as Freiburg's eco-neighbourhoods - their carbon footprints are enlarged greatly by their consumption practices and leisure travel. Economic activity and 
๑. urban density in post-industrial cities are 崖 inextricably linked with global networks of production, consumption and distribution.

\section{KEY PLAYERS}

It has become conventional wisdom that city leaders are more nimble and less ideological than their national counterparts. These two qualities, the story goes, allow leaders such as New York's former mayor Michael Bloomberg and former Bogotá mayor Enrique Peñalosa, along with networks such as the C40 Large Cities Leadership Group, to take the lead in confronting global sustainability challenges - even as international treaty efforts and national policymaking stall.

This 'urban turn' in policy and discourse captures important truths. But it obscures the fact that municipalities are more nimble because they wield less power. Municipal governments lack access to industrial policy, welfare systems and tax regimes. They have limited control over consumption patterns and large-scale infrastructure. And cities are bound by competitive pressures that pit them against each other in the pursuit of capital investment and talented workers. Municipalities thus tend to pursue sustainability policies that are also economic-development policies, and these disproportionately focus on affluent central business districts or residential areas designed to attract skilled professionals.

This challenges, for instance, the good intent of the United Nations' Sustainable Development Goals for cities. Reaching these goals requires strong national policy commitments to new regional infrastructure programmes, cash transfers to poor people, and local governance reform across urban regions.

State, provincial and national governments can apply sustainability policies across local jurisdictional lines. In the aftermath of Hurricane Sandy, which hit the US east coast in 2012, some of the dozens of small municipalities on the New Jersey Shore independently attempted to build new 'hard' seawalls, despite concerns that these would displace storm surges to their neighbours. Only higher levels of government can prevent such 'beggar-thy-neighbour' local politics.

And grass-roots groups bring about change from the bottom up. Communitybased organizations, city-wide non-profit organizations and ad hoc social movements shape cities' built environment and lifestyle. But these groups are often overlooked in discussions about sustainability policy because most of them do not frame their work in environmental terms. They are more likely to speak of a broader 'right to the city'. Advocates for affordable housing and mass transit are proposing exactly the types of intervention that shrink individuals' carbon footprints and improve community resilience ${ }^{8}$. But they are rarely seen as

\section{REMOTE IMPACTS}

In San Francisco, most of the carbon emissions associated with the consumption of goods by residents, firms and governments in 2008 arose beyond the city's limits - elsewhere in the United States or overseas. Yet municipal sustainability initiatives target only the metropolitan area.

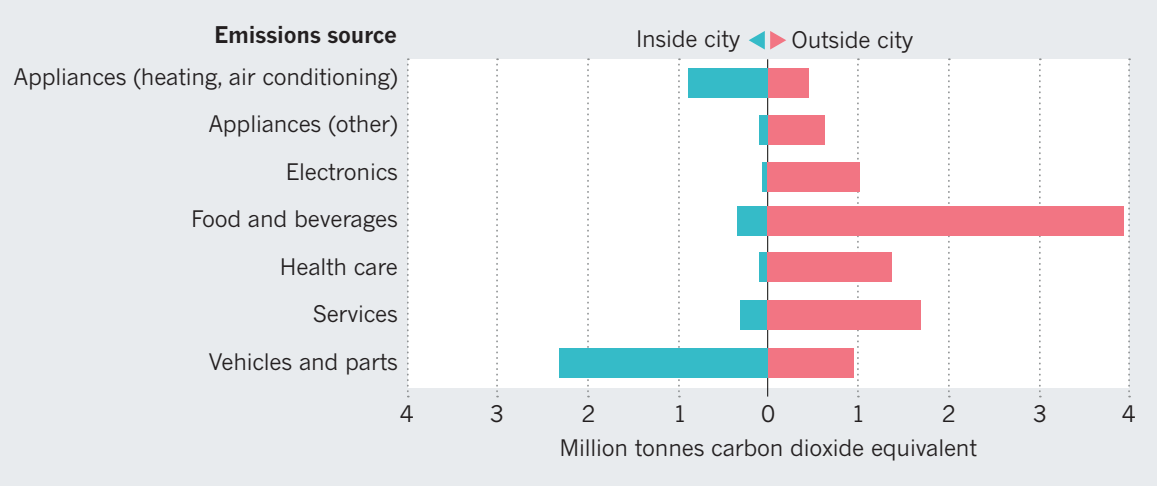

prospective allies by green policymakers.

Sustainability efforts that are indifferent to concerns about affordability and that lack support from community members are less just and less likely to succeed. In New York City, an effort to implement a congestion charge in central Manhattan failed in the face of public opposition. New Yorkers in outer boroughs viewed the plan as elitist and indifferent to the concerns of poorer commuters. Still, some fledgling coalitions around equity and sustainability are emerging. Last year in São Paulo, a historic drought and state mismanagement of scarce water resources led housing movements and environmentalists - long at odds over how to deal with precarious waterside settlements - to come together around a common agenda of housing and water justice?

\section{NEXT STEPS}

First, urban environmental researchers need to supplement neighbourhood-specific and city-centric ${ }^{10}$ measurements, such as walkability or commuting by public transport, with ones that better capture the broader dimensions of ecological sustainability and social equity. For instance, studies of changes to local transit systems should analyse the knock-on effects in regional housing and labour markets.

Second, multicity low-carbon policy networks such as the C40 and climate-focused organizations such as the World Resources Institute in Washington DC should insist on - and support - all large cities carrying out standardized, consumption-based carbonfootprint analyses. As well as providing more accurate accounts of specific cities' carbon footprints, this would underscore the extent to which emissions levels are correlated with class and income.

Third, policymakers should treat social equity and ecological effectiveness as mutually reinforcing dynamics in urban sustainability. They should bring the widest range of social movements to the table and see those groups' demands - such as revitalizing rent regulation and public housing - as central. This would entail more frequent meetings of larger groups of stakeholders and different metrics of policy success. But it would also yield more creative, sophisticated and encompassing policies that would have broader public support.

Only by expanding the spatial and social dimensions of urban policymaking can it be made truly sustainable and equitable.

David Wachsmuth is assistant professor in the School of Urban Planning, McGill University, Montreal, Canada. Daniel Aldana Cohen is assistant professor in the Department of Sociology, University of Pennsylvania, Philadelphia, Pennsylvania, USA. Hillary Angelo is assistant professor in the Department of Sociology, University of California, Santa Cruz, Santa Cruz, California, USA.

e-mail:david.wachsmuth@mcgill.ca

1. Checker, M. City Soc. 23, 210-229 (2011).

2. Mössner, S. \& Miller, B. Regions Magazine $\mathbf{3 0 0 ,}$ 18-20 (2015).

3. Anguelovski, I. et al. J. Plan. Educ. Res. http:// dx.doi.org/10.1177/0739456X16645166 (2016).

4. Pellow, D. N. in In the Nature of Cities: Urban Political Ecology and the Politics of Urban Metabolism (eds Heynen, N. et al.) 226-244 (Routledge, 2006).

5. Bawden, T. 'Global warming: Data centres to consume three times as much energy in next decade, experts warn' The Independent (23 January 2016); available at http://go.nature. com/2aym $x 8 \mathrm{~h}$

6. Stanton, E. A. et al. Consumption-Based Emissions Inventory For San Francisco Version 2.0 (Stockholm Environment Institute-US Center, 2011); available at http://go.nature. com/2arawxw

7. Heinonen, J. et al. Environ. Res. Lett. 8, 035050 (2013).

8. Ageyman, J., Bullard, R. D. \& Evans, B. Just Sustainabilities: Development in an Unequal World (MIT Press, 2003).

9. Cohen, D. A. Public Cult. 28, 261-289 (2016).

10.Angelo, H. \& Wachsmuth, D. Int. J. Urban Reg. Res. 39, 16-27 (2015). 